\title{
Awareness and attitude of spectacle wearers to alternatives to corrective eyeglasses
}

\author{
Abdulkabir Ayansiji Ayanniyi,, ${ }^{1}$ Fatai Olasunkanmi Olatunji, ${ }^{2}$ \\ Ramatu Yahaya Hassan, ${ }^{3}$ Bola Josephine Adekoya, ${ }^{4}$ \\ Kehinde Fasasi Monsudi, ${ }^{5}$ Abubakar Mustapha Jamda ${ }^{6}$ \\ 'Department of Ophthalmology, College of Health Sciences, University of Abuja, \\ Nigeria; \\ ${ }^{2}$ Department of Ophthalmology, College of Health Sciences, University of Ilorin, \\ Nigeria; \\ ${ }^{3}$ Department of Ophthalmology, Usmanu Dan Fodiyo University, Sokoto, Nigeria; \\ ${ }^{4}$ Department of Ophthalmology, Lagos State University Teaching Hospital, Ikeja, \\ Nigeria; \\ ${ }^{5}$ Department of Ophthalmology, Federal Medical Centre, Birnin Kebbi, Nigeria; \\ ${ }^{6}$ Department of Community Medicine, College of Health Sciences, University of \\ Abuja, Nigeria.
}

\begin{abstract}
Aim: It has been observed that potential beneficiaries rarely request for alternatives to corrective eyeglasses in our setting. The objective of this study was to determine awareness and attitude towards alternatives to spectacle correction, specifically; contact lens and refractive eye surgery among spectacle wearers in a resource-limited setting.

Methods: A cross-sectional survey of 214 spectacle wearers in seven Nigerian hospitals using semi-structured questionnaire. Information sought included demographic characteristics, awareness, and attitudes to contact lens and refractive eye surgery as well as reasons for the poor interest in alternatives to eyeglasses.

Results: There were 93 males and 121 females, with a mean age of 40.2 years (SD 15.8.). Most, 198 (92.6\%) had at least secondary education. Ninety-eight (45.8\%) and 113 (52.8\%) patients were aware of the options of contact lens and refractive eye surgery respectively, but 171 (80\%) were averse to wearing contact lenses or having refractive eye surgery. Reasons given included lack of information, high cost, and possible complications that may arise. Higher education was significantly associated with participants' awareness of alternatives to eyeglasses (contact lens $[P=0.016]$, refractive eye surgery $[P=0.009]$ ) but not with willingness to use contact lens $(P=0.96)$ or refractive eye surgery $(P=0.425)$.

Conclusion: There was relatively high awareness but low willingness to use alternatives to corrective eyeglasses among users. Education on alternatives to corrective eyeglasses, allaying fears on their complications, and making them more affordable could enhance awareness and create a more positive attitude towards them.
\end{abstract}

Key words: Attitude, awareness, spectacle correction, contact lens, refractive surgery, refractive errors

Correspondence: Dr. Abdulkabir Ayansiji Ayanniyi, Department of Ophthalmology, College of Health Sciences, University of Abuja, Nigeria.

E-mail: ayanniyikabir@yahoo.com 


\section{Introduction}

Correction of uncorrected refractive errors is a priority of Vision 2020 - The Right to Sight, ${ }^{1}$ and the use of spectacles or eyeglasses has been meeting this important need across the globe. ${ }^{2-4}$ Nevertheless, there are alternatives to eyeglasses for correcting refractive errors, and they may be indicated for scenarios such as vocational demands as may be necessary for sports men and women, to correct anisometropia, or just for some patients who cherish varieties and dislike having no alternatives. ${ }^{5}$ Also, it may be medically indicated, for instance, visual rehabilitation could be better using contact lenses instead of eyeglasses following repaired cornea injury. ${ }^{6-9}$ In rural settings, stigmatization associated with eyeglasses may also prevent potential beneficiaries from using them even when they are given free of charge.

Important alternatives to corrective eyeglasses include contact lenses and refractive eye surgeries. These alternatives are not only effective in correcting refractive errors but also give the individual options to wearing spectacles. ${ }^{9}$ These alternatives can also contribute to the reduction of the burden of uncorrected refractive error. This would be possible as patients who may have reason(s) not to wear eyeglasses could choose to pick alternatives. In a study in India, nearly $44 \%$ of spectacle wearers discontinued on account of incorrect prescription or spectacle discomfort. ${ }^{10}$ The study further revealed as many as two-thirds of those with spherical equivalent +3.00DS or worse were not using eyeglasses due to poor quality of refractive service. This implied the use of spectacles to correct uncorrected refractive error in the population was sub-optimal ${ }^{10}$ and alternatives might be required to complement corrective eyeglasses.

Individuals having refractive errors especially many spectacle wearers are potential beneficiaries of contact lenses and refractive eye surgeries. However, spectacle wearers rarely request for alternatives to eyeglasses in correcting refractive errors in resource limited setting. This study was conducted to determine awareness, attitude and reasons for the poor interest among spectacle wearers to contact lens and refractive eye surgery in a resource limited economy.

\section{Methods}

This was a prospective descriptive cross-sectional study conducted at seven different health facilities in Nigeria. This study was carried out following the guidelines as contained in the declaration of Helsinki and approval was obtained from ethic committee of University of Abuja Teaching hospital, Nigeria. The participants were patients who came for eye consultations in the eye clinics of the health facilities.

\section{Study design}

The criteria for inclusion of the participants in the study were age 18 years and above, current use of eyeglasses for a period not less than six months, and consenting to participate in the study. Written consent was obtained after the study had been explained to each participant. Each of the participants was interviewed using a 
semi-structured questionnaire. The questionnaire had been previously pre-tested at one of the health facilities, among wearers who were not included in the analysis. The questionnaire sought participants' demographic characteristics, awareness, and attitudes to contact lens and refractive eye surgery. Also sought, were reasons for the wearers' poor interest in alternatives to eyeglasses.

\section{Data analysis}

The data were collated, entered into SPSS 15.0 (Chicago, IL), and analyzed. The Chi square was used to test associations between parameters. These include associations between educational level and awareness of contact lenses as alternative to corrective eyeglasses, awareness of refractive eye surgeries, and willingness to wear contact lenses instead of eyeglasses. Others include associations between gender and preference for contact lenses; associations between duration of eyeglasses use and awareness of contact lenses as alternative to eyeglasses, and willingness to use contact lenses. The associations of statistical significance was taken at $\mathrm{P}<0.05$.

\section{Results}

Two hundred and fourteen participants including 93 (43.5\%) males and 121 (56.5\%) females were interviewed. Age range was between 18 and 84 years, with a mean of 40.2 (SD 15.8) years. Most 198 (92.6\%), had at least secondary education (Table 1). Seventeen $(7.9 \%)$ admitted to having systemic allergy or asthma while $28(13.1 \%)$ worked in a dusty environment.

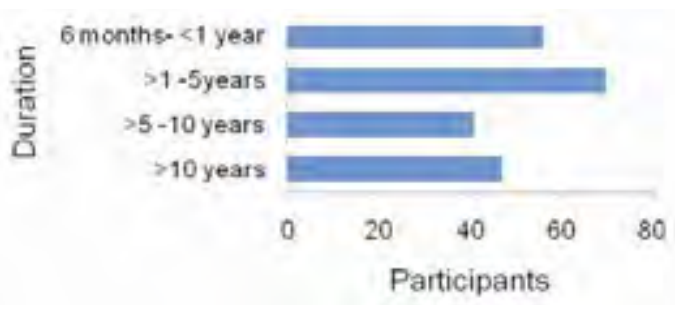

Fig. 1. Duration of eyeglasses use among participants.

Most, 158 (74\%) had worn eyeglasses for at least one year (Fig. 1). Almost half of the participants were aware of contact lens $98(45.8 \%)$, and refractive eye surgery $113(52.8 \%)$ as options to correct refractive errors.

Only $56(26.2 \%)$ rated their interest to use contact lenses (Fig. 2). However, most participants were averse to wearing contact lenses or having refractive eye surgery (Table 2). Most participants gave reasons for not willing to wear contact lenses, $163(76 \%)$ and undergo refractive surgery, 154 (72\%) instead of corrective eyeglasses (Fig. 3). Higher education was significantly associated with participants' awareness of alternatives to eyeglasses (contact lens $[P=0.016]$, refractive eye surgery $[P=0.009]$ ) but not with willingness to use contact lens $(P=0.96)$ or refractive eye surgery $(P=$ 0.425)(Table 2). Also, the duration of eyeglasses use was not significantly associated with participants' awareness that contact lens could be used instead of eyeglasses $(P=0.46)$, as well as willingness to use them $(P=0.16)$. The gender was not significantly associated with participants willingness to use contact lens $(P=0.19)$, or refractive eye surgery $(P=0.49)$ instead of eyeglasses (Table 3 ). 


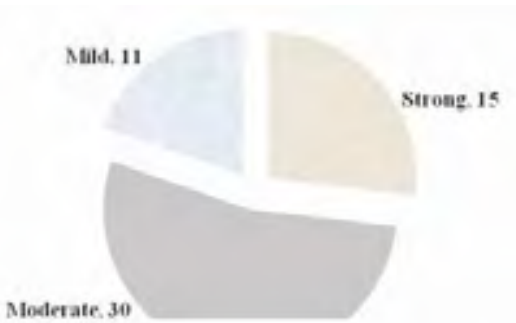

Fig. 2. Rating of interest in wearing contact lenses.

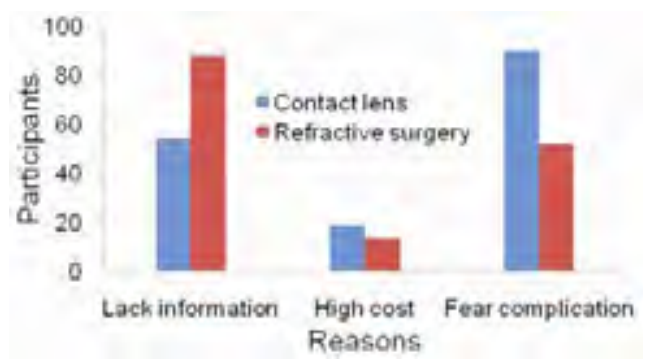

Fig. 3. Reasons for non preference of alternatives to eyeglasses.

Table 1. Demographic distribution of the participants $(n=214)$.

\begin{tabular}{|l|l|}
\hline Characteristic & $\mathbf{n}(\%)$ \\
\hline Occupation & $57(26.6)$ \\
\hline Schooling & $26(12.2)$ \\
\hline Teaching & $66(30.8)$ \\
\hline Civil service & $20(9.4)$ \\
\hline Pensioner & $18(8.4)$ \\
\hline Trading & $12(5.6)$ \\
\hline Artisan & $15(7.0)$ \\
\hline Others & \multicolumn{2}{|l|}{} \\
\hline Marital status & $70(32.7)$ \\
\hline Single & $139(65.0)$ \\
\hline Married & $5(2.3)$ \\
\hline Widowed & $97(22.0)$ \\
\hline Education levels attained & \multicolumn{2}{|l|}{} \\
\hline Tertiary & $7(3.2)$ \\
\hline Secondary & \\
\hline Primary & \\
\hline No formal education & \\
\hline & \\
\hline
\end{tabular}


Table 2. Associations of education, awareness of and willingness to use alternatives to eyeglasses.

\begin{tabular}{|c|c|c|c|c|c|c|}
\hline \multirow[t]{3}{*}{$\begin{array}{l}\text { Education } \\
\text { Level }\end{array}$} & \multicolumn{6}{|c|}{ Awareness of alternatives to corrective eyeglasses } \\
\hline & \multicolumn{3}{|c|}{ Contact lens } & \multicolumn{3}{|c|}{ Refractive eye surgery } \\
\hline & Yes & No & Total & Yes & No & Total \\
\hline None & 1 & 6 & 7 & 2 & 5 & 7 \\
\hline Primary & 1 & 8 & 9 & 3 & 6 & 9 \\
\hline Secondary & 18 & 29 & 47 & 19 & 27 & 46 \\
\hline Tertiary & 77 & 72 & 149 & 89 & 50 & 139 \\
\hline \multirow[t]{2}{*}{ Total } & 97 & 115 & 212 & 113 & 88 & 201 \\
\hline & \multicolumn{3}{|c|}{ Pearson Chi-square $=10.304, \mathrm{df}=3, \mathrm{P}=0.016$} & \multicolumn{3}{|c|}{ Pearson Chi-square $=11.691, \mathrm{df}=3, P=0.009$} \\
\hline \multirow[t]{3}{*}{$\begin{array}{l}\text { Education } \\
\text { Level }\end{array}$} & \multicolumn{6}{|c|}{ Willingness to use alternatives to corrective eyeglasses } \\
\hline & \multicolumn{3}{|c|}{ Contact lens } & \multicolumn{3}{|c|}{ Refractive eye surgery } \\
\hline & Yes & No & Total & Yes & No & Total \\
\hline None & 1 & 6 & 7 & 1 & 5 & 6 \\
\hline Primary & 1 & 8 & 9 & 2 & 7 & 9 \\
\hline Secondary & 8 & 37 & 45 & 11 & 34 & 45 \\
\hline Tertiary & 24 & 111 & 135 & 21 & 127 & 148 \\
\hline \multirow[t]{2}{*}{ Total } & 34 & 162 & 196 & 35 & 173 & 208 \\
\hline & \multicolumn{3}{|c|}{ Pearson Chi-square $=0.313, \mathrm{df}=3, \mathrm{P}=0.958$} & \multicolumn{3}{|c|}{ Pearson Chi-square $=2.789, \mathrm{df}=3, \mathrm{P}=0.425$} \\
\hline
\end{tabular}

Significant level $\mathrm{P}<0.05$ 
Table 3. Associations of duration of eyeglass use, gender, and awareness of and willingness to use alternatives to eyeglasses

\begin{tabular}{|c|c|c|c|c|c|c|}
\hline \multirow[t]{2}{*}{ Duration } & \multicolumn{3}{|c|}{$\begin{array}{l}\text { Awareness of contact lens } \\
\text { as alternatives to corrective } \\
\text { eyeglasses }\end{array}$} & \multicolumn{3}{|c|}{$\begin{array}{l}\text { Willingness to wear contact lens } \\
\text { instead of corrective eyeglasses }\end{array}$} \\
\hline & Yes & No & Total & Yes & No & Total \\
\hline$<1$ year & 22 & 33 & 55 & 5 & 48 & 53 \\
\hline 1-5 year & 30 & 41 & 71 & 15 & 48 & 63 \\
\hline 6-10 year & 21 & 19 & 40 & 8 & 28 & 36 \\
\hline$>10$ year & 24 & 22 & 46 & 6 & 38 & 44 \\
\hline \multirow[t]{2}{*}{ Total } & 97 & 115 & 212 & 34 & 162 & 196 \\
\hline & \multicolumn{3}{|c|}{ Pearson Chi-square $=2.581, \mathrm{df}=3, \mathrm{P}=0.461$} & \multicolumn{3}{|c|}{ Pearson Chi-square $=5.169, \mathrm{df}=3, P=0.160$} \\
\hline \multirow[t]{3}{*}{ Gender } & \multicolumn{6}{|c|}{ Willingness to use alternatives to corrective eyeglasses } \\
\hline & \multicolumn{3}{|c|}{ Contact lens } & \multicolumn{3}{|c|}{ Refractive eye surgery } \\
\hline & Yes & No & Total & Yes & No & Total \\
\hline Male & 18 & 66 & 84 & 17 & 73 & 90 \\
\hline Female & 16 & 96 & 112 & 18 & 100 & 118 \\
\hline \multirow[t]{2}{*}{ Total } & 34 & 162 & 196 & 35 & 173 & 208 \\
\hline & \multicolumn{3}{|c|}{ Pearson Chi-square $=1.708, \mathrm{df}=1, \mathrm{P}=0.191$} & \multicolumn{3}{|c|}{ Pearson Chi-square $=0.482, \mathrm{df}=1, P=0.488$} \\
\hline
\end{tabular}

Significant level $\mathrm{P}<0.05$

\section{Discussion}

Globally, there are advances and increasing uptake of alternative means of correcting refractive errors including contact lenses and refractive eye surgeries. ${ }^{9}$ This study determined the awareness, attitude and reasons for the poor interest among spectacle wearers to contact lens and refractive eye surgery as alternatives in a resource limited setting. The spectacle wearers were the subjects of this study being potential beneficiaries of contact lenses and refractive eye surgeries. Interest in corrective options to refractive errors was expected to be more among spectacle wearers compared to the general population. The participants' demographic characteristics suggested a matured population (mean age 40.2 years) and most likely to have a reliable opinion on the sought issue. This study found a relatively high level of awareness among participants on alternatives to eyeglasses in 
correcting refractive errors despite the fact that the alternatives were not available in all the facilities where this study took place. However, education was found to be significantly associated with the level of awareness on alternatives to eyeglasses in correcting refractive errors among the participants as observed in other studies on health related conditions. ${ }^{11,12}$ This might not be surprising as increased level of education might translate to increase exposure of the individual. However, discordance existed between the participants' level of education and their willingness to wear contact lenses instead of eyeglasses.

The participants' poor attitude to possible uptake of both contact lenses and refractive eye surgeries as alternatives to corrective eyeglasses were borne out of the fact that most participants had very little information about them and, thought alternatives would be expensive. Possible complication arising from them was also part of the reasons given for the reluctance to use these alternatives. The aforesaid factors appeared to have overriding effect on wearers' demographic characteristics such as gender, length of spectacle wear and willingness to wear contact lenses. Getting consumers informed about available services could enhance positive attitude to such services. ${ }^{13}$ As in this study, cost is a known barrier to uptake of eye care services especially, in resource limited communities. ${ }^{14,15}$ On the other hand, studies have implicated the fear of complications of eye procedure including eye surgery as a barrier to eye care services. ${ }^{16,17}$

Individuals with allergic ocular conditions are not ideal candidates for contact lenses or refractive eye surgery, and someone working in a dusty environment is generally discouraged from wearing contact lenses. This is so because of the difficulty such individuals may face including hypersensitivity to contact lens solutions in allergic condition and visual impairment following collection of dust on the surface of contact lenses. ${ }^{18}$

This study revealed the need to popularize alternatives to eyeglasses in resourcelimited setting in order to optimize the correction of refractive errors thereby reducing the magnitude of uncorrected refractive error across the globe. While each of eyeglasses, contact lenses and refractive eye surgery alone may be sufficient in correcting uncorrected refractive errors in many patients, some patients may need a combination of these corrective options to achieve optimal correction and satisfaction.

For practical, economic and psychosocial reasons many patients with uncorrected refractive errors would continue to benefit from eyeglasses. Nevertheless, popularizing contact lenses and refractive surgery have potential to optimize reduction in magnitude of uncorrected refractive errors. For instance, visual rehabilitation is better with contact lenses in cases of irregular astigmatism such as keratoconus, cornea scarring, anisometropia and aphakia. ${ }^{18}$ Also, customized contact lenses should be a better choice for patients with congenital albinism. ${ }^{18}$

Interestingly, and for many reasons, many patients would or could not use eyeglasses and 'suffer in silence' with uncorrected refractive errors. Those would not, might be doing so fearing 'social stigma' of wearing glasses or enmeshed in 'unfounded belief' that eyeglasses damage eyes as reported across societies. 19,21 
Such individuals are potential beneficiaries of alternatives to eyeglasses.

Moreover, those who desire normal vision for instance without glasses, such as professional athletes including footballers and hockey players would benefit from alternatives, eliminating possible eyeglasses' hazards and encumbrance. ${ }^{18}$

\section{Conclusion}

There was relative high awareness and negative attitude to alternatives to corrective eyeglasses among participants. Target audience education on alternatives to corrective eyeglasses, allaying fears on their complications and affordable cost could enhance awareness and positive attitudinal change. The need to popularize alternatives to eyeglasses in correcting refractive errors in resource-limited community is underscored.

\section{Acknowledgement}

The authors thank all spectacle wearers who participated in this study.

\section{References}

1. Pizzarello L, Abiose A, Ffytche T, Duerksen R, Thulasiraj R, Taylor H, et al. Vision 2020: the right to sight. A global initiative to eliminate avoidable blindness. Arch Ophthalmol 2004;122:615-620.

2. Bourne RRA, Dineen BP, Huq DMN, Ali SM, Johnson GJ. Correction of refractive error in the adult population of Bangladesh: Meeting the unmet need. Invest Ophthalmol Vis Sci 2004;5:410-417.

3. Naidoo K, Ravilla D. Delivering refractive error services: primary eye care centres and outreach. Community Eye Health Journal 2007;20:42-44.

4. Patel I, West SK. Presbyopia: prevalence, impact, and interventions. Community Eye Health Journal 2007;20:40-41.

5. Piipo LJ, Coats DK. Pediatric spectacle prescription. Comprehensive Ophthalmology. Update 2002;3:113-122.

6. Titiyal JS, Sinha R, Sharma N, Sreenivas V, Vajpayee RB. Contact lens rehabilitation following repaired corneal perforations. BMC Ophthalmology 2006;6:11doi:10.1186/1471- 2415-6-11.

7. Jupiter DJ, Katz HR. Management of irregular astigmatism with rigid gas permeable contact lenses. CLAO J 2000;26:14-16.

8. Jain IS, Mohan K, Gupta A. Unilateral traumatic aphakia in children: role of corneal contact lenses. J Pediatr Ophthalmol and Strab 1985;22:137-139.

9. Solomon KD, Fernández de Castro LE, Sandoval HP, Biber JM, Groat B, Neff KD, et al. Joint LASIK Study Task Force. LASIK world literature review: quality of life and patient satisfaction. Ophthalmology 2009;116:691-701.

10. Dandona R, Dandona L, Kovai V, Giridhar P, Prasad MN, Srinivas M. Population based study of spectacles use in southern India. Indian J Ophthalmol 2002;50:145-155.

11. Dandona R, Dandona L, John RK, McCarty CA, Rao GN. Awareness of eye diseases in an urban population in southern India. Bulletin World Health Organization 2001;79:96-102.

12. Sannapaneni K, Vilas K, Marmamula S, Bindiganavale SR, Gullapalli RN, Ravi T. Awareness of glaucoma in the rural population of Southern India. Community Ophthalmology 2005; 53:205-208.

13. Ayanniyi AA, Bob-Egbe S, Olatunji FO, Omolase, CO, Omolade EO, Ojehomon, FO, et al. Social Marketing Potential of Qualitative Cost Free to Patient Eye Care Programme in a Nigerian Community. Annals of African Medicine 2009;8:225-228.

14. Mpyet C, Dineen BP, Solomon AW. Cataract surgical coverage and barriers to uptake of cataract surgery in leprosy villages of north eastern Nigeria. Br J Ophthalmol 2005;89:936-938.

15. Gyasi ME, Amoaku WMK, Asamany DK. Barriers to Cataract Surgical Uptake in the Upper East Region of Ghana. Ghana Medical Journal 2007;41:167-170.

16. Olatunji FO, Ayanniyi AA. Anxieties of Ophthalmic Surgical Patients About Ophthalmic Surgery. 
Nigerian Journal of Ophthalmology 2007;15:10-12.

17. Finger RP, Ali M, Earnest J, Nirmalan PK. Cataract Surgery in Andhra Pradesh State, India: An Investigation into uptake Following Outreach Screening Camps. Ophthalmic Epidemiol 2007;14:327-332.

18. Stein HA, Slatt BJ, Stein RM. Editors. The ophthalmic assistant: a guide for ophthalmic medical assistant. USA: Mosby, 1994.

19. Congdon N, Zheng M, Sharma A, Choi K, Song Y, Zhang M, et al. Prevalence and determinants of spectacle nonwear among rural Chinese secondary schoolchildren: The Xichang Pediatric Refractive Error Study Report 3. Arch Ophthalmol 2008;126:1717-1723.

20. Li L, Song Y, Liu X, Lu B, Choi K, Lam DS et al. Spectacle Acceptance among Secondary School Students in Rural China: The Xichang Pediatric Refractive Error Study (X-PRES)-Report 5. Invest Ophthalmol Vis Sci 2008;49:2895-2902.

21. Odedra N, Wedner SH, Shigongo ZS. Barriers to spectacle use in Tanzanian secondary school students. Ophthalmic Epidemiol 2008;15:410-417. 